\title{
Early treatment with isoflurane improves cardiac function and increases survival in a rat model of TAKO-TSUBO cardiomyopathy
}

\author{
J Oras $^{1 *}$, B Redfors ${ }^{2}$, E Omerovic ${ }^{2}$, S Ricksten ${ }^{1}$, H Seemann-Lodding ${ }^{1}$ \\ From ESICM LIVES 2015 \\ Berlin, Germany. 3-7 October 2015
}

\section{Introduction}

Tako-tsubo cardiomyopathy (TCM) is an acute cardiac syndrome with severe hypokinesia of the left ventricle (LV), often affecting the apex causing apical ballooning and heart failure. Sympathetic stress is a trigger of TCM and is probably underdiagnosed and not uncommon in ICU patients [1]. We have developed an experimental rat model of TCM, in which LV apical akinesia develops after intraperitoneal (i.p.) injection of isoprenaline with many similarities to clinical TCM [2]. We recently demonstrated that pre-treatment with isoflurane could prevent the development of LV apical akinesia in this TCM animal model [3].

\section{Objectives}

In the present study, we examined whether isoflurane, when used for treatment, could attenuate the degree of LV dysfunction and reduce mortality in a TCM animal model.

\section{Methods}

TCM was induced in seventy-five propofol sedated animals by intraperitonial injection of isoprenaline $(50 \mathrm{mg} / \mathrm{kg})$. Within 90 minutes after injection, the animals develop tako-tsubo-like heart failure with apical dyskinesia/akinesia and reduced cardiac output [2]. The animals were randomized to either inhalation with no isoflurane (CONTROL, $\mathrm{n}=15$ ) or inhalation with $1 \%$ isoflurane before (ISOFL 0 , $\mathrm{n}=15$ ), $10 \min$ (ISOFL 10, $\mathrm{n}=15$ ), $30 \mathrm{~min}$ (ISOFL 30, $\mathrm{n}=15$ ) and 120 min (ISOFL 120, $\mathrm{n}=15$ ) after induction of TCM. Evaluation of cardiac function with echocardiography was performed 90 minutes after isoprenaline in all animals.

${ }^{1}$ Sahlgrenska University Hospital, Anesthesiology and Intensive Care Medicine, Gothenburg, Sweden

Full list of author information is available at the end of the article
Extent of apical akinesia was expressed as percentage of LV endocardial length that was akinetic. After the experimental procedure, the animals were monitored for 48 hours for assessment of survival.

\section{Results}

Early institution of treatment with isoflurane, attenuated the degree of LV dysfunction after isoprenaline injection, as the degree of akinesia was lower in ISOFL 0 , ISOFL 10, ISOFL 30 compared to CONTROL (Figure 1). 48 hours survival was higher in ISOFL 0 , ISOFL 10, ISOFL 30 versus CONTROL, while there was no difference in 48 hours survival between ISOFL 120 and CONTROL (Figure 2). In a multivariable model, isoflurane inhalation within 30 minutes (ISOFL 0, ISOFL 10, ISOFL 30), was an independent predictor of 48 hour survival.

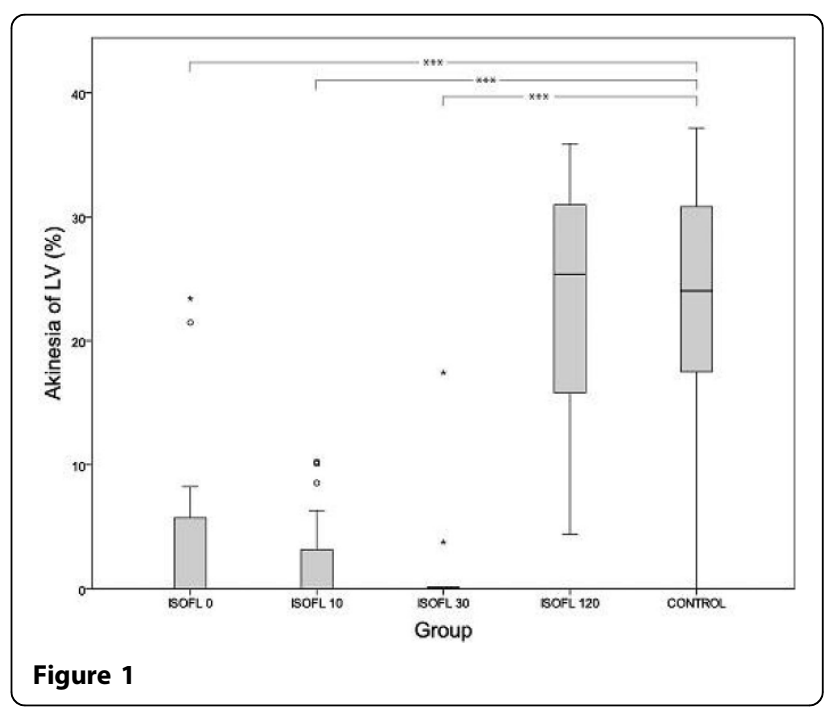

(c) 2015 Oras et al.; This is an Open Access article distributed under the terms of the Creative Commons Attribution License (http:// creativecommons.org/licenses/by/4.0), which permits unrestricted use, distribution, and reproduction in any medium, provided the original work is properly cited. 


\begin{tabular}{|lrlr|}
\hline \multicolumn{4}{c|}{48 h survivor } \\
Group & \multicolumn{1}{l|}{ Yes } & \multicolumn{1}{c|}{ No } & Sig. vs CONTROL \\
ISOFL O (N, \%) & $12(80)$ & $3(20)$ & $<0.001$ \\
ISOFL 10 (N, \%) & $10(67)$ & $5(33)$ & 0.008 \\
ISOFL 30 (N, \%) & $12(80)$ & $3(80)$ & $<0.001$ \\
ISOFL 120 (N, \%) & $2(13)$ & $13(87)$ & 1.0 \\
CONTROL (N, \%) & $2(13)$ & $13(87)$ & - \\
Figure 2 & & & \\
\hline
\end{tabular}

\section{Conclusions}

In this animal model of TCM, isoflurane treatment, when started early after induction of TCM, highly attenuated degree of LV apical akinesia. This was accompanied by a clearly improvement of survival. Isoflurane sedation in the ICU could be a beneficial strategy in patients suffering from hyper-adrenergic conditions.

\section{Authors' details}

${ }^{1}$ Sahlgrenska University Hospital, Anesthesiology and Intensive Care

Medicine, Gothenburg, Sweden. 'Sahlgrenska University Hospital, Wallenberg

Laboratory, Gothenburg, Sweden.

Published: 1 October 2015

\section{References}

1. Park, et al: Left ventricular apical ballooning due to severe physical stress in patients admitted to the medical ICU. Chest 2005.

2. Shao, et al: Novel rat model reveals important roles of $\beta$-adrenoreceptors in stress-induced cardiomyopathy. Int J Cardiol 2013.

3. Redfors, Oras, et al: Cardioprotective effects of isoflurane in a rat model of stress-induced cardiomyopathy (takotsubo). Int J Cardiol 2014.

doi:10.1186/2197-425X-3-S1-A800

Cite this article as: Oras et al:: Early treatment with isoflurane improves cardiac function and increases survival in a rat model of TAKO-TSUBO cardiomyopathy. Intensive Care Medicine Experimental 2015 3(Suppl 1): A800.

\section{Submit your manuscript to a SpringerOpen ${ }^{\odot}$ journal and benefit from:}

- Convenient online submission

- Rigorous peer review

- Immediate publication on acceptance

- Open access: articles freely available online

- High visibility within the field

- Retaining the copyright to your article 